\title{
Subcutaneous Nodular Fasciitis
}

National Cancer Institute

\section{Source}

National Cancer Institute. Subcutaneous Nodular Fasciitis. NCI Thesaurus. Code C48961.

A self-limiting, rapidly growing, non-encapsulated benign neoplasm arising from the subcutaneous tissues. It is characterized by the growth of plump spindle-shaped fibroblasts in a storiform pattern, multinucleated osteoclast-like giant cells, red blood cell extravasation, chronic inflammatory cells, and high mitotic activity. 